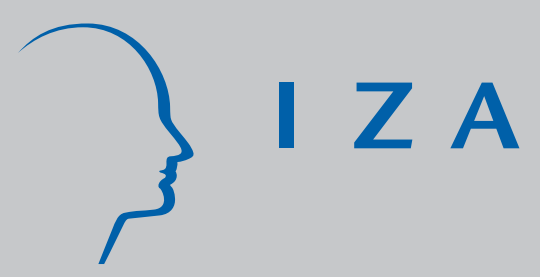

IZA DP No. 3790

Measuring Richness and Poverty:

A Micro Data Application to Europe and Germany

Andreas Peichl

Thilo Schaefer

Christoph Scheicher

October 2008 


\title{
Measuring Richness and Poverty: A Micro Data Application to Europe and Germany
}

\author{
Andreas Peichl \\ IZA, ISER and University of Cologne \\ Thilo Schaefer \\ $C P E$, University of Cologne \\ Christoph Scheicher \\ University of Cologne
}

Discussion Paper No. 3790

October 2008

\author{
IZA \\ P.O. Box 7240 \\ 53072 Bonn \\ Germany \\ Phone: +49-228-3894-0 \\ Fax: +49-228-3894-180 \\ E-mail: iza@iza.org
}

\begin{abstract}
Any opinions expressed here are those of the author(s) and not those of IZA. Research published in this series may include views on policy, but the institute itself takes no institutional policy positions.

The Institute for the Study of Labor (IZA) in Bonn is a local and virtual international research center and a place of communication between science, politics and business. IZA is an independent nonprofit organization supported by Deutsche Post World Net. The center is associated with the University of Bonn and offers a stimulating research environment through its international network, workshops and conferences, data service, project support, research visits and doctoral program. IZA engages in (i) original and internationally competitive research in all fields of labor economics, (ii) development of policy concepts, and (iii) dissemination of research results and concepts to the interested public.
\end{abstract}

IZA Discussion Papers often represent preliminary work and are circulated to encourage discussion. Citation of such a paper should account for its provisional character. A revised version may be available directly from the author. 


\section{ABSTRACT \\ Measuring Richness and Poverty: A Micro Data Application to Europe and Germany ${ }^{*}$}

In this paper, we define a new class of richness measures. In contrast to the often used headcount, these new measures are sensitive to changes in rich persons' income and therefore allow for a more sophisticated analysis of richness. We demonstrate the application of these new measures to analyze the development of poverty and richness over time in Germany, to compare Germany to many other European countries and to investigate the impact of tax reforms on poverty and richness. Using these examples, we show the importance of taking into account the intensity of changes and not only the number of people beyond a given richness line (headcount). We propose to use the new measures in addition to the headcount index for a more comprehensive analysis of richness.

JEL Classification: D31, H23, I32

Keywords: richness, affluence, poverty, tax reform, flat tax

Corresponding author:

Andreas Peichl

IZA

P.O. Box 7240

53072 Bonn

Germany

E-mail: peichl@iza.org

\footnotetext{
* We would like to thank Jean-Yves Duclos, James Foster, Clemens Fuest, Stephen Jenkins, Peter Lambert, Joachim Merz, John Micklewright, Karl Mosler, Emmanuel Saez, Stephan Klasen and three anonymous referees for their helpful contributions.
} 


\section{Introduction}

The financing problems of European welfare states and the increasing pressure of global economic competition have given rise to a debate whether the gap between rich and poor is widening in general and as a consequence of recently implemented reforms of the tax and transfer system in particular. Poverty at the bottom of the income distribution has been in the spotlight of both academic research and political discussion since a long period of time. Quantitative studies of income poverty are for example Krause and Wagner (1997) or Hanesch et al. (2000) for Germany, and Atkinson (1997) and de Vos and Zaidi (1997) comparing European countries. ${ }^{1}$ While it is indisputable that society should ensure a certain minimum subsistence level, the top of the income distribution has just recently become a particular focus of attention, especially in the context of income tax reform. Studies on income richness ${ }^{2}$ are for example Krause and Wagner (1997) or Merz (2004). Since 2000, the German parliament has been demanding regular governmental reports on poverty and richness (see Bundesregierung, 2001, 2005, 2008). Many recent tax reforms proposals with a tendency to lower (marginal) tax rates have been criticized for redistributing from the poor to the rich (see e.g. OECD (2006)). It is widely believed that the rich are getting richer and the poor are getting poorer.

Given this debate, appropriate summary measures, which provide additional information beyond analyzing the inequality of the whole income distribution, are of key importance for an empirical assessment of the development of poverty and richness. Several poverty indices have been developed in the long tradition of the literature on measuring income poverty. Measuring income richness is a less considered field. As far as we know, empirical studies mainly use the population share of rich persons (headcount ratio) to measure income richness. ${ }^{3}$ However, the headcount is not a satisfying measure for either poverty or richness. It is only concerned with the number of people below (above) a cutoff. Therefore, if nobody changes his or her status, an income change will not affect this index.

\footnotetext{
${ }^{1} \mathrm{~A}$ microsimulation study of the effects of a minimum pension policy to reduce poverty in several European countries can be found in Atkinson et al. (2002).

${ }^{2}$ We use richness as a synonym for affluence in this paper.

${ }^{3}$ There is a series of recent papers using income shares to analyze the top income distribution (see, e.g., Atkinson (2005), Dell (2005), Piketty (2005), Saez (2005), Saez and Veall (2005), Piketty and Saez (2006), Atkinson and Piketty (2007), Aaberge and Atkinson (2008), Roine and Waldenström (2008)).
} 
Looking for a more sophisticated measure of richness, this paper contributes by defining a new class of richness indices analogous to well-known measures of poverty. Our approach is more sophisticated because it takes the intensity of changes and not only the number of people beyond a given richness line into account. To demonstrate the usefulness of these new measures, we analyze three empirical problems: firstly, we look at the development of poverty and richness indices over time in Germany (ex post longitudinal analysis). Secondly, we compare the values of these indices for Germany with different European countries (cross-country analysis). Thirdly, we compute the values of these indices for different reform proposals of the German tax and transfer system (ex ante analysis). Our analysis is based on household micro data provided by GSOEP, EU-SILC and the microsimulation model FiFoSiM.

The empirical application reveals that our new measures expand the results beyond a pure headcount analysis. We find distinctive differences in our longitudinal analysis of the development of richness in Germany. It depends on the measure whether richness is increasing (headcount) or decreasing (some of the new measures) regarding various time periods. The new measures also clarify differing effects of the German reunification. When comparing affluence in countries across Europe, our new measures reveal additional information beyond the proportion of rich people. The composition of "the rich" is also accounted for by the newly defined measures. The cross-country analysis yields different groups of countries according to their values of poverty and richness indices. In general, Eastern and Southern European countries as well as AngloSaxon countries are characterized by rather high poverty and richness, whereas Continental and Northern European countries can be distinguished by rather small values of poverty and richness. Finally, our analysis of flat tax reform proposals for Germany shows the difference between concave and convex measurement empirically. These empirical examples demonstrate the usefulness of our new measures. We suggest to use them in addition to the headcount index for a more comprehensive analysis of richness.

The setup of the paper is organized as follows: section 2 describes well-known poverty indices. In section 3 we define analogue indices of richness and report the main differences. In section 4 we describe the micro data used for the analysis. Section 5 reports the results of our empirical analysis for Germany and the European cross-country analysis. Section 6 concludes. 


\section{Poverty indices}

Many poverty indices have been proposed in the literature. ${ }^{4}$ We focus on a class of indices that contains the two most common measures, the headcount and the Foster et al. (1984) indices (FGT).

Consider a net income distribution $x=\left(x_{1}, x_{2}, \ldots, x_{n}\right) \in R_{+}^{n}$, where $n$ is the number of individuals or households. Let $\pi$ be the poverty line, e.g. $60 \%$ of the median income, and $p=\#\left\{i \mid x_{i}<\pi, i=1,2, \ldots, n\right\}$ the number of poor persons.

We consider poverty indices $\varphi$ of the form

$$
\varphi(x)=\frac{1}{n} \sum_{i=1}^{n} u\left(\frac{x_{i}}{\pi}\right)
$$

where $u: R_{+} \rightarrow R_{+}$is decreasing on $[0,1)$ and vanishes on $[1, \infty)$. Examples are:

- The proportion of poor persons (headcount) is defined as

$$
\varphi^{H C}(\mathbf{x})=\frac{1}{n} \sum_{i=1}^{n} \mathbf{1}_{x_{i}<\pi}=\frac{p}{n},
$$

with $\mathbf{1}_{x_{i}<\pi}=1$, for $x_{i}<\pi$ and $\mathbf{1}_{x_{i}<\pi}=0$ elsewhere.

- The Foster et al. (1984) indices (FGT) are defined by

$$
\varphi_{\alpha}^{F G T}(x)=\frac{1}{n} \sum_{i=1}^{n}\left(\left(1-\frac{x_{i}}{\pi}\right)_{+}\right)^{\alpha}=\frac{1}{n} \sum_{i=1}^{n}\left(\max \left\{1-\frac{x_{i}}{\pi}, 0\right\}\right)^{\alpha}
$$

with $\alpha>0$ and $(y)_{+}:=\max \{y, 0\}$. The coefficient $\alpha$ may be interpreted as a parameter of poverty aversion, since greater values of $\alpha$ attach increasingly greater weight to large poverty gaps.

- Other examples of this form (1) are the indices by Watts (1968) and Chakravarty (1983).

\footnotetext{
${ }^{4}$ See Zheng (1997) or Chakravarty and Muliere (2004) for recent surveys of the vast literature.
} 


\section{New measures of richness}

Before we define new measures of affluence or richness, we give a short review of the sparse literature and on desirable properties.

\subsection{Review of the literature}

While all poverty indices of the previous section are well-known, little research has been done on the measurement of richness at the top of the income distribution. For an overview of the sparse literature see Medeiros (2006). The first challenge is to define an affluence or richness line. We define it analogously to the poverty line as a cutoff income point above (below) which a person or household is considered to be rich (non-rich). Like the poverty line, it is possible to define the richness line in absolute terms (e.g. 1 million Euros) or relative terms (e.g. 200\% of the median or the mean income).

Let $\rho$ be the richness line and $r=\#\left\{i \mid x_{i}>\rho, i=1,2, \ldots, n\right\}$ the number of rich persons. In many studies on income richness, only the proportion of rich persons is used as a measure of richness:

$$
R^{H C}(\mathbf{x})=\frac{1}{n} \sum_{i=1}^{n} \mathbf{1}_{x_{i}>\rho}=\frac{r}{n}
$$

with $\mathbf{1}_{x_{i}>\rho}=1$, for $x_{i}>\rho$ and $\mathbf{1}_{x_{i}>\rho}=0$ elsewhere. Its definition resembles that of the poverty headcount ratio. But if we want to compare different tax and transfer reform scenarios, this is not a satisfying definition of richness: if nobody changes his or her status (rich or non-rich), neither a change in a rich person's income nor a transfer between rich persons will change this index. Medeiros (2006) defined an affluence gap by

$$
R^{M e d}(\mathbf{x})=\frac{1}{n} \sum_{i=1}^{n}\left(x_{i}-\rho\right)_{+}=\frac{1}{n} \sum_{i=1}^{n} \max \left\{x_{i}-\rho, 0\right\}
$$

The advantage of this definition compared to the headcount is that this affluence gap is increasing in income. However, Medeiros' index of richness is not standardized and is an absolute measure of richness. $R^{\text {Med }}$ is proportional in income implicitly, i.e. a transfer between two rich persons will not change the index. Further on, this absolute index is not scale invariant, 
i.e. multiplying all incomes with a scalar increases $R^{M e d}$ by this factor. To overcome these drawbacks, we propose a standardized approach of richness measures bounded by the unit interval. Such a standardization is important because we want to make the indices of richness commensurable to indices of poverty, and it will be discussed in further detail below.

\subsection{Desirable properties of richness indices}

The general idea for measuring richness analogously to poverty is to take into account the number of rich people as well as the intensity of richness. Thereby, an index of affluence is constructed as the weighted sum of the individual contributions to affluence. The weighting function of the index shall have some desirable properties which are derived following the literature on axioms for poverty indices.

Multiple axioms have been suggested in literature on poverty measurement (see e.g. Sen (1976), Chakravarty and Muliere (2004), Foster et al. (1984)). We translate these axioms to the measurement of richness as desirable properties that an index of affluence should satisfy ${ }^{5}$ :

- Focus axiom: a richness index shall be independent of the incomes of the non-rich.

- Continuity axiom: the index shall be a continuous function of incomes, i.e. small changes in the income structure shall not lead to discontinuously large changes in the richness index.

- Monotonicity axiom: a richness index shall increase if c.p. the income of a rich person increases.

- Subgroup decomposability axiom: the overall degree of richness may be decomposed into the (population) weighted sum of subgroup richness indices.

The transfer axiom of poverty measurement cannot be translated one-to-one to richness measurement and has to be discussed in more detail. A poverty index satisfies the transfer axiom if

\footnotetext{
${ }^{5}$ We do not give a formal notation of these axioms but rather state them informally, although they can be easily noted mathematically precise.
} 
the index decreases when a rank-preserving progressive transfer from a poor person to someone who is poorer takes place. This property can be translated to richness measurement in two different ways:

- Transfer axiom T1 (concave $\left.)^{6}\right)$ : a richness index shall increase when a rank-preserving progressive transfer between two rich persons takes place.

- Transfer axiom T2 (convex): a richness index shall decrease when a rank-preserving progressive transfer between two rich persons takes place.

The question behind the definition of these two opposite axioms is: shall an index of richness increase if $(i)$ a billionaire gives an amount $x$ to a millionaire, or $(i i)$ if the millionaire gives the same amount $x$ to the billionaire. This question cannot be answered without moral judgement. In the following subsection, we define a general class of richness measures which allows to apply both transfer axioms. However, we argue that the concave transfer axiom (T1) is more appropriate in the context of the analysis of tax benefit systems.

\subsection{Defining a new class of richness measures}

\subsubsection{General class}

In general, a richness index satisfying the four axioms and either T1 or T2 can be defined analogously to the general class of poverty indices in equation (1) as

$$
R(\mathbf{x}, \rho)=\frac{1}{n} \sum_{i=1}^{n} f\left(\frac{x_{i}}{\rho}\right)
$$

where $f$ is a continuous (except for the headcount), strictly increasing function that is either concave (for T1) or convex (for T2). We use strictly increasing transformations because the indices of affluence should be sensitive to higher incomes, i.e. satisfy the monotonicity axiom. To fulfill the focus axiom, a person with an income not higher than $\rho$ should not influence the

\footnotetext{
${ }^{6}$ Unless otherwise stated, concave and convex are meant in the strict sense.
} 
measure of richness, i.e. $f\left(\frac{x_{i}}{\rho}\right)=0$, for $x_{i} \leq \rho$. To fulfill the subgroup decomposability axiom, the index of richness has to be additively decomposable, i.e. the affluence index is a weighted sum of several household subgroups:

$$
R(\mathbf{x}, \rho)=\sum_{m=1}^{M} \frac{n_{m}}{n} R_{m}(\mathbf{x}, \rho)
$$

for any given richness line $\rho, M$ population subgroups indexed $m=1, \ldots, M, n_{m}$ the number of people and $R_{m}(\mathbf{x}, \rho)$ the richness index of subgroup $m$ with the same overall richness line $\rho$.

\subsubsection{Concave class $(\mathrm{T} 1)^{7}$}

As mentioned above, an important difference between the measurement of poverty and richness concerns the transfer axiom. In poverty measurement decreasing the income of a very poor person shall have a larger effect than increasing the income of a less poor person (minimal transfer axiom). We propose that an affluence index shall be less sensitive to changes of very high incomes, i.e. a progressive transfer between rich persons increases affluence (concave transfer axiom $(\mathrm{T} 1))$. Formally spoken $f$ has to be concave. The relative incomes $\frac{x_{i}}{\rho}$ then have to be transformed by a function that is concave on $(1, \infty)$.

The technical reason for the concavity in our approach is the possibility to standardize the index. Many poverty indices are standardized such that the individual extent of poverty has the value one if a person has no income at all, and zero if a person has income at or above the poverty line. If we translate this into measurement of affluence, a person with income at or below the affluence line would contribute zero to the affluence index and contribute nearly one if he is "very, very rich". However, there is an obvious difference between the income classes of the poor and of the rich: the incomes of the poor are bounded by 0 and $\pi$, but the incomes of the rich only have a lower bound $\rho$. The problem here is that it is not obvious how to transform the incomes of the rich to the unit interval. ${ }^{8}$ We transform the incomes of the rich relative to the affluence line, $\frac{x_{i}}{\rho}$, to the unit interval by a strictly increasing transformation function $f$,

\footnotetext{
${ }^{7}$ We call the richness index concave or convex if the individual affluence function $f$ is concave or convex.

${ }^{8}$ If the individual contribution to the affluence index, e.g. for the affluence gap $x_{i}-\rho$, is divided by $x^{\max }-\rho$ ( or $x^{\max }$ ), i.e. the affluence of the richest person with income $x^{\max }$, the index will not fulfill the monotonicity axiom, since increasing the income of the richest person will decrease the index.
} 
with $\lim _{y \rightarrow \infty} f(y)=1$. Alternative functions that are non-concave, i.e. either linear or convex, do not allow for a standardization and, therefore, individual affluence will be unbounded in these cases.

Of course, choosing a concave function is a normative judgment. Therefore, beside the technical argument, we give four arguments to support our point of view and argue why we prefer a concave function:

Firstly, to decide in which society there is more affluence, we use the "equiprobability model for moral value judgments" of Harsanyi (1977). A risk averse decision maker with diminishing marginal utility in income (the standard assumption in economic theory) has to decide between two populations. The second population is obtained from the first by some progressive transfers between rich persons, i.e. money is transferred from the richer to the less rich rich person. The decision maker does not know what his position will be in the societies. He will prefer the second population since the expected utility will be higher there. Therefore, a concave utility (or value) function with diminishing marginal utility in income supports a concave value function for the richness index.

Secondly, a more equal distribution of the rich will lead to a more homogenous group with probably more equal interests and, therefore, more influence on decisions of the society. Thus, the concerns of the rich are more visible and important in that population. This view can be somehow seen as the "polarization view", i.e. richness is increasing when the homogeneity of the top of the distribution and, therefore, c.p. the polarization increases. ${ }^{9}$

The third point is that people are rather envious of a rich dentist living next door gaining several hundred thousand euros, but admire superstars, far away via TV, gaining several millions or admire a self made billionaire like Bill Gates. ${ }^{10}$ This assertion supports the concave view, i.e. that Bill Gates' individual affluence and its contribution to a measure of richness does not increase very much if he receives another million (diminishing marginal utility). Whereas the individual affluence of the dentist increases tremendously if he received that million.

The fourth argument is that we have to look how societies treat their rich people, especially how

\footnotetext{
${ }^{9}$ The contrast to this point of view is the "inequality view" which would be satisfied if richness increased when inequality (among the rich) increased. This view is satisfied with the convex transfer axiom (T2).

${ }^{10}$ Cf. Lockwood and Kunda (1997) and the psychological literature cited there.
} 
they tax them. Usually, a progressive tax system is applied where the (marginal) tax payments are a concave function of taxable income. However, the marginal tax rate increases only up to a certain income level and remains constant above. In this way we get the accepted point of view implicitly. In Germany for example, there is a maximum tax rate of $42 \%$ (in 2006) and progression ends close to the richness line.

Taking all this into account, we define measures of affluence $R$ by

$$
R(\mathbf{x}, \rho)=\frac{1}{n} \sum_{i=1}^{n} f\left(\frac{x_{i}}{\rho}\right)
$$

where $f: R_{+} \rightarrow[0,1]$ is strictly increasing and concave on $(1, \infty){ }^{11}$

If we use $f(y):=\left(1-\frac{1}{y}\right)^{\alpha} \cdot \mathbf{1}_{y>1}$, with $\alpha \in(0,1)$, we obtain an affluence index $R_{\alpha}^{F G T, T 1}$, that resembles the FGT index of poverty satisfying T1:

$$
R_{\alpha}^{F G T, T 1}(\mathbf{x}, \rho)=\frac{1}{n} \sum_{i=1}^{n}\left(1-\frac{1}{\left(\frac{x_{i}}{\rho}\right)} \mathbf{1}_{x_{i}>\rho}\right)^{\alpha}=\frac{1}{n} \sum_{i=1}^{n}\left(\left(\frac{x_{i}-\rho}{x_{i}}\right)_{+}\right)^{\alpha}, \quad \alpha \in(0,1)
$$

The new affluence index increases with a progressive transfer between a rich and a very rich person $(\mathrm{T} 1)$, since $\left(\frac{x-\rho}{x}\right)^{\alpha}$ is concave on $(\rho, \infty)$, for $0<\alpha<1$.

We may also employ $f(y)=\left(1-\frac{1}{y^{\beta}}\right) \cdot \mathbf{1}_{y>1}, \beta>0$ and obtain an index analogous to the poverty index of Chakravarty (1983):

$$
R_{\beta}^{C h a}(\mathbf{x}, \rho)=\frac{1}{n} \sum_{i=1}^{n}\left(1-\left(\frac{\rho}{x_{i}}\right)^{\beta}\right)_{+}, \beta>0
$$

Obviously, $f(y)=\left(1-\left(\frac{\rho}{y}\right)^{\beta}\right)$ is concave for $y>\rho$ and $\beta>0$ (T1). One can easily see that $R_{1}^{F G T, T 1}(\mathbf{x}, \rho)=R_{1}^{C h a}(\mathbf{x}, \rho)$ for $\alpha=\beta=1$. Further on, for $\alpha \rightarrow 0$ and $\beta \rightarrow \infty, R_{\alpha \rightarrow 0}^{F G T, T_{1}}$ and $R_{\beta \rightarrow \infty}^{C h a}$ respectively resemble the headcount index $R^{H C}$.

The advantage of $R_{\beta}^{C h a}$ over $R_{\alpha}^{F G T, T_{1}}$ is the possibility to construct indices with "slowly" increasing functions $f$ (see Figure 1) whereas $R_{\alpha}^{F G T, T_{1}}$ is not concave for $\alpha>1$. Therefore, we

\footnotetext{
${ }^{11} \mathrm{~A}$ case, without standardization is the Watts (1968) measure of affluence, i.e. $\pi=\rho, f(y)=\ln (y)$ for $y>1$.
} 
will use $R_{\beta}^{C h a}(\mathbf{x}, \rho)$ in the remainder of this paper as our concave measure of affluence.
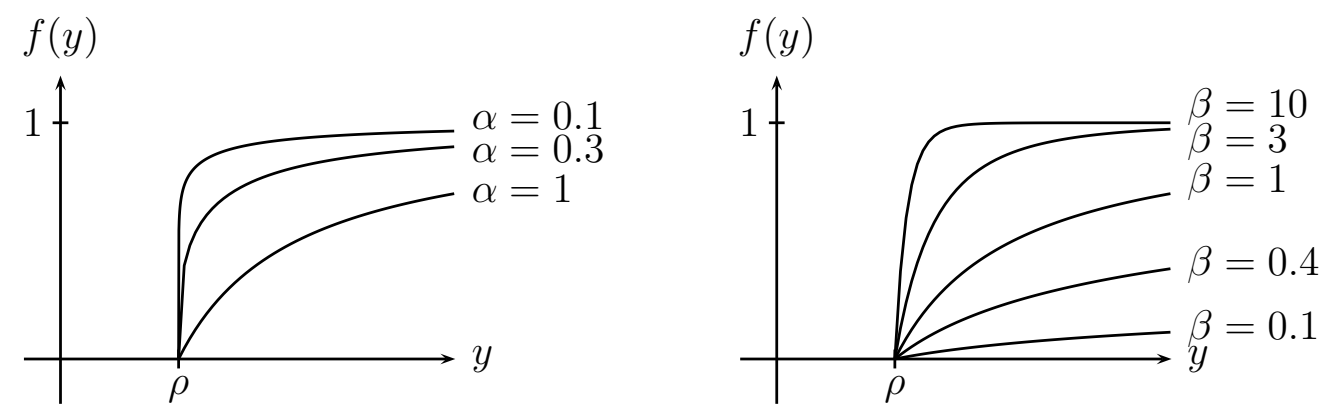

Figure 1: Graphs of $f(y)$ for $R_{\alpha}^{F G T, T_{1}}$ (left hand side) and $R_{\beta}^{C h a}$ (right hand side), for different $\alpha$ and $\beta$.

Nevertheless, there is a drawback to our concave approach. We are not able to postulate a strong transfer axiom, i.e. how a progressive transfer between a rich and a non-rich (who becomes rich) will change the affluence index. The following example shows this problem:
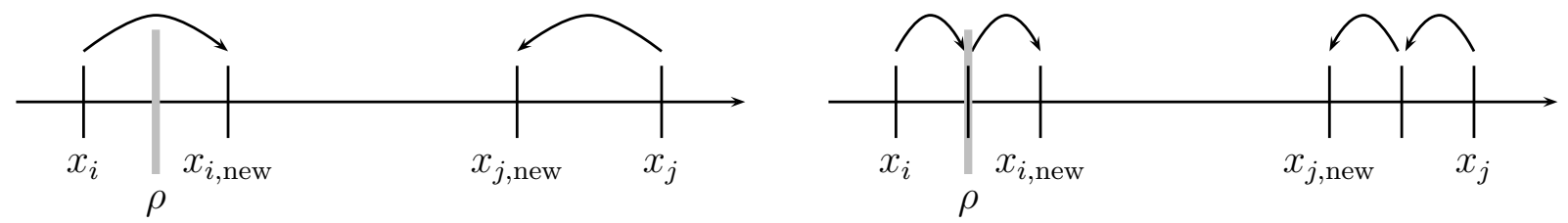

Figure 2: Transfers between a rich and a non-rich.

If we split a progressive transfer between a rich person and a non-rich person that becomes rich in two transfers (see Figure 2, right hand side), the first transfer decreases the affluence of person $j$ because of the monotonicity axiom, whereas we do not care for person $i$ because of the focus axiom. The second transfer increases affluence. Altogether, for a progressive transfer with a change from non-rich to rich, it is not clear whether affluence increases or decreases. This is different to poverty measurement, where we can split such a transfer in two transfers and poverty decreases in both steps.

\subsubsection{Convex class (T2)}

Although we think a concave weighting function $f$ is more appropriate due to reasons given above, it is still possible to define measures of affluence $R(\mathbf{x}, \rho)$ (equation 4 ) satisfying the 
convex transfer axiom T2 by

$$
R(\mathbf{x}, \rho)=\frac{1}{n} \sum_{i=1}^{n} f\left(\frac{x_{i}}{\rho}\right), \quad \alpha>1
$$

where $f$ is strictly increasing and convex on $(1, \infty)$.

If we use $f(y):=(y-1)^{\alpha}$ for $y>1$, with $\alpha>1^{12}$, we obtain an affluence index $R_{\alpha}^{F G T, T 2}$, that resembles the FGT index of poverty satisfying T2:

$$
R_{\alpha}^{F G T, T 2}(\mathbf{x}, \rho)=\frac{1}{n} \sum_{i=1}^{n}\left(\frac{x_{i}}{\rho}-1\right)^{\alpha} \cdot \mathbf{1}_{x_{i}>\rho}=\frac{1}{n} \sum_{i=1}^{n}\left(\left(\frac{x_{i}-\rho}{\rho}\right)_{+}\right)^{\alpha}
$$

This affluence index decreases by a progressive transfer between a rich and a very rich person (T2), since $\left(\frac{x-\rho}{\rho}\right)^{\alpha}$ is convex on $(\rho, \infty)$ for $\alpha>1$. We will use this index in the remainder of this paper as our convex measure of affluence, which we compare with the concave $R_{\beta}^{C h a}$.

\subsection{Examples}

We now illustrate some properties of our new measures by small examples:

Example 1: A change in a rich person's income shall change the measure of richness (monotonicity axiom): Consider two populations with income distribution

$$
\mathbf{x}=(5,5,5,11,11) \text { and } \mathbf{y}=(5,5,5,100,100)
$$

Let $\rho_{\mathbf{x}}, \rho_{\mathbf{y}}$ be $200 \%$ of the median income. Then $\rho_{\mathbf{x}}=\rho_{\mathbf{y}}=10$ and we obtain

$$
R^{H C}(\mathbf{x}, \rho=10)=R^{H C}(\mathbf{y}, \rho=10)=0.400
$$

\footnotetext{
${ }^{12}$ Note that for $\alpha \in(0,1) f$ is concave and we have a non-standardized version of the concave FGT.
} 
and

$$
\begin{aligned}
R_{\beta=1}^{C h a}(\mathbf{x})=0.036 \quad \text { and } & R_{\beta=1}^{C h a}(\mathbf{y})=0.360, \\
R^{M e d}(\mathbf{x})=0.400 \quad \text { and } & R^{M e d}(\mathbf{y},)=36, \\
R_{\alpha=2}^{F G T, T 2}(\mathbf{x})=0.004 \quad \text { and } & R_{\alpha=2}^{F G T, T 2}(\mathbf{y},)=32.4 .
\end{aligned}
$$

The results for the measures $R_{\beta=1}^{C h a}, R^{M e d}$ and $R_{\alpha=1}^{F G T, T 2}$ all indicate that (the intensity of) richness is lower in the population $\mathbf{x}$, i.e. $R(\mathbf{x})<R(\mathbf{y}){ }^{13}$

Example 2: Transfer axiom T1 (T2): A richness index shall be less (more) sensitive to changes of very high incomes: Let

$$
\mathbf{x}=(5,5,5,11,9989) \text { and } \mathbf{y}=(5,5,5,1000,9000)
$$

where $\mathbf{y}$ is obtained from $\mathbf{x}$ by a progressive transfer of 989 monetary units between the two rich persons. Again we obtain

$$
R^{H C}(\mathbf{x})=R^{H C}(\mathbf{y})=0.400
$$

but quite different results for the intensity measures:

$$
\begin{aligned}
R_{\beta=1}^{C h a}(\mathbf{x})=0.218 \quad \text { and } \quad & R_{\beta=1}^{C h a}(\mathbf{y})=0.398 \\
R^{M e d}(\mathbf{x})=1996 \quad \text { and } \quad & R^{M e d}(\mathbf{y})=1996, \\
R_{\alpha=2}^{F G T, T 2}(\mathbf{x})=19,916,088 \quad \text { and } & R_{\alpha=2}^{F G T, T 2}(\mathbf{y})=16,360,039 .
\end{aligned}
$$

According to $R_{\beta=1}^{C h a}$, richness is lower in population $\mathbf{x}$ which is in line with the concave transfer axiom T1, i.e. a richness index shall increase with a progressive transfer. The values of the absolute $R^{M e d}$ index is the same in both populations, indicating that redistribution takes place only among the rich subpopulation. As expected, $R_{\alpha=2}^{F G T, T 2}(\mathbf{x})>R_{\alpha=2}^{F G T, T 2}(\mathbf{y})$, i.e. this richness

\footnotetext{
${ }^{13}$ Note that multiplying all incomes by a scalar, e.g. 2, leaves all relative richness measures unchanged (scale invariance), whereas the value of the absolute richness measure $R^{\text {Med }}$ doubles.
} 
index decreases with a progressive transfer between two rich persons. A drawback of this approach, however, is that these indices are not standardized.

\section{Data and methodology}

Our analyses are based on three different data sources. For the analysis of the development of the indices in Germany, we use panel data from the GSOEP. Data from the EU-SILC is used for the cross-country comparison, whereas data provided by the microsimulation model FiFoSiM is used for the analysis of tax reforms. All three sources are described in the following subsections.

\subsection{GSOEP}

The German Socio-Economic Panel (GSOEP) is a representative panel study of private households in Germany since 1984. It includes in each wave the incomes of the previous year. In 2007, GSOEP consists of about 12,000 households with more than 30,000 individuals. The data include information on earnings, employment, occupational and family biographies, health, personal satisfaction, household composition and living situation. ${ }^{14}$

\subsection{EU-SILC}

EU-SILC (European Union Statistics on Income and Living Conditions) is the successor of ECHP data. The EU-SILC collects comparable cross-sectional and longitudinal multidimensional micro data on income and social exclusion in European countries. Since 2005 the dataset has been covering 25 EU member states, plus Norway and Iceland, and is the largest comparative survey of European income and living conditions.

\footnotetext{
${ }^{14}$ See SOEP Group (2001) or Haisken De-New and Frick (2003) for a more detailed introduction to GSOEP.
} 


\subsection{FiFoSiM}

FiFoSiM is a behavioral microsimulation model for the German tax and transfer system using income tax and household survey microdata. The approach of FiFoSiM is innovative insofar as it creates a dual database using two micro datasets for Germany: FAST01 and GSOEP. ${ }^{15}$ FAST01 is a micro dataset from the German federal income tax statistics 2001 containing the relevant income tax data of nearly 3 million households in Germany. For our second data source, the German Socio-Economic Panel (GSOEP), see section 4.1.

The layout of the tax benefit module follows several steps: firstly, the database is updated using the static ageing technique which allows controlling for changes in global structural variables and a differentiated adjustment for different income components of the households. Secondly, we simulate the current tax and benefit system in 2006, using the uprated data. This allows us to compute the disposable income for each person, taking into account the detailed rules of the complex tax benefit system. The modeling of the tax and transfer system uses the technique of microsimulation. ${ }^{16}$ FiFoSiM computes individual tax payments for each case in the sample, considering gross incomes and deductions in detail. The individual results are multiplied by the individual sample weights to extrapolate the fiscal effects of the reform with respect to the whole population. After simulating the tax payments and the received benefits, we can compute the disposable income for each household. The result of this simulation is the benchmark for different reform scenarios which are also modeled by using the modified database and applying the different tax benefit rules using the technique of microsimulation. A detailed description of the FiFoSiM simulation model can be found in Peichl and Schaefer (2006).

\subsection{Income concept and methodology}

We use the disposable income defined as market income minus direct taxes and social contributions plus cash benefits (including pensions) for our analyses. The unit of analysis is the individual. To compensate for different household structures and possible economies of scale

\footnotetext{
${ }^{15}$ In the last years several tax benefit microsimulation models for Germany have been developed (see for example Wagenhals (2004)). Most of these models use either GSOEP or FAST data. FiFoSiM is so far the first model to combine these two databases.

${ }^{16}$ Cf. Gupta and Kapur (2000) or Harding (1996) for an introduction to the field of microsimulation.
} 
in households, we use equivalent incomes throughout the analyses. For each person, the equivalent (per-capita) total net income is its household's total disposable income divided by the equivalent household size according to the modified OECD scale. ${ }^{17}$

The poverty (richness) line is $60 \%$ (200\%) of median equivalent income. Choosing the richness line as twice the median is arbitrary but common practice (see e.g. Medeiros (2006)). However, when analyzing richness, choosing the richness line is not as problematic as choosing the poverty line (usually $60 \%$ of median income) because the upper parts of the income distribution are not as dense as the lower parts.

To account for the regional differences in Germany after reunification, we adjust the incomes with the consumer price index of the respective region provided in the GSOEP data. We therefore express all incomes in prices of 2000. To account for regional differences across Europe, we use PPP-adjusted incomes.

\section{$5 \quad$ Empirical applications}

In this section, we show that the new measures are not only theoretically interesting, as explained by the hypothetical examples in section 3.4, but also provide extra explanatory value when analyzing empirical data. ${ }^{18}$ We present three empirical applications to illustrate the difference of our affluence measures to the common headcount index.

\subsection{Development of poverty and richness in Germany}

The first empirical application is the longitudinal analysis of the development of poverty and richness in Germany since the early 1980s. Table 1 presents the values for the median equivalent income $(p 50)$, which is used to define the poverty (60\%) and richness (200\%) lines, the Gini index

\footnotetext{
${ }^{17}$ The modified OECD scale assigns a weight of 1.0 to the head of household, 0.5 to every household member aged 14 or more and 0.3 to each child aged less than 14. Summing up the individual weights gives the household specific equivalence factor.

${ }^{18}$ Notice, we show that in fact from year to year, country to country or scenario to scenario the different indices develop differently. However, we do not claim that the data are very accurate such that every change of a measure reflects an actual change in the population: Nevertheless, we show that under usual conditions the choice of the indices and the underlying judgments does matter.
} 
of inequality $\left(I_{G}\right)$, the poverty indices (headcount and $\varphi^{F G T}$ ) and several richness measures (headcount, the concave $R_{\beta}^{C h a}$ and the convex $R^{M e d}$ and $R_{\alpha}^{F G T, T 2}$ ).

\begin{tabular}{r|rr|rrr|rrrrr} 
year & $p 50$ & $I_{G}$ & $\varphi^{H C}$ & $\varphi_{\alpha=1}^{F G T}$ & $\varphi_{\alpha=2}^{F G T}$ & $R^{H C}$ & $R_{\beta=0.3}^{C h a}$ & $R_{\beta=3}^{C h a}$ & $R^{M e d}$ & $R_{\alpha=2}^{F G T, T 2}$ \\
\hline 1983 & 13.0 & 0.264 & 12.8 & 3.1 & 1.4 & 5.8 & 0.48 & 2.7 & 650 & 3.2 \\
1984 & 13.0 & 0.271 & 13.0 & 3.3 & 1.5 & 5.7 & 0.51 & 2.8 & 753 & 5.6 \\
1985 & 13.1 & 0.263 & 12.7 & 3.2 & 1.5 & 5.8 & 0.43 & 2.5 & 601 & 3.7 \\
1986 & 13.8 & 0.253 & 12.0 & 3.0 & 1.4 & 5.4 & 0.39 & 2.4 & 519 & 2.0 \\
1987 & 14.2 & 0.254 & 12.1 & 3.3 & 1.6 & 6.1 & 0.39 & 2.4 & 521 & 1.8 \\
1988 & 14.6 & 0.259 & 12.5 & 3.3 & 1.5 & 5.5 & 0.41 & 2.4 & 631 & 3.4 \\
1989 & 14.7 & 0.262 & 12.3 & 3.4 & 1.8 & 5.5 & 0.44 & 2.6 & 688 & 3.7 \\
1990 & 15.1 & 0.259 & 13.1 & 3.4 & 1.6 & 5.6 & 0.42 & 2.5 & 625 & 2.4 \\
1991 & 14.7 & 0.262 & 12.9 & 3.5 & 1.7 & 5.9 & 0.39 & 2.4 & 564 & 2.4 \\
1992 & 14.9 & 0.268 & 13.4 & 3.7 & 1.9 & 6.3 & 0.44 & 2.7 & 630 & 2.2 \\
1993 & 14.6 & 0.273 & 13.3 & 3.8 & 1.9 & 6.9 & 0.52 & 3.2 & 740 & 2.7 \\
1994 & 14.3 & 0.281 & 14.7 & 4.5 & 2.4 & 7.0 & 0.53 & 3.1 & 773 & 3.6 \\
1995 & 14.6 & 0.275 & 14.0 & 4.3 & 2.3 & 6.8 & 0.50 & 3.0 & 715 & 3.0 \\
1996 & 14.6 & 0.271 & 13.3 & 4.1 & 2.2 & 6.8 & 0.51 & 3.1 & 724 & 2.6 \\
1997 & 14.5 & 0.268 & 13.8 & 4.2 & 2.1 & 7.0 & 0.42 & 2.7 & 596 & 2.4 \\
1998 & 14.7 & 0.266 & 12.3 & 3.7 & 1.9 & 7.0 & 0.46 & 2.9 & 637 & 2.1 \\
1999 & 15.2 & 0.275 & 14.0 & 4.2 & 2.2 & 7.3 & 0.49 & 3.1 & 718 & 2.8 \\
2000 & 15.5 & 0.270 & 13.7 & 4.2 & 2.1 & 6.7 & 0.46 & 2.9 & 684 & 2.3 \\
2001 & 15.4 & 0.288 & 15.3 & 4.5 & 2.2 & 7.8 & 0.58 & 3.5 & 901 & 3.8 \\
2002 & 15.8 & 0.283 & 15.6 & 4.6 & 2.2 & 7.6 & 0.52 & 3.3 & 775 & 2.2 \\
2003 & 15.6 & 0.287 & 16.4 & 4.9 & 2.3 & 7.4 & 0.52 & 3.2 & 777 & 2.7 \\
2004 & 15.3 & 0.291 & 17.3 & 5.0 & 2.4 & 8.1 & 0.54 & 3.4 & 778 & 2.7 \\
2005 & 15.1 & 0.311 & 18.8 & 5.5 & 2.5 & 8.4 & 0.72 & 4.1 & 1157 & 5.6 \\
2006 & 15.1 & 0.307 & 17.3 & 5.1 & 2.3 & 8.7 & 0.72 & 4.1 & 1150 & 7.0
\end{tabular}

Table 1: Values (in $\%$ except $p 50$ (in 1000 Euro), $I_{G}, R^{M e d}$ ) of the poverty and richness indices using GSOEP data (equivalent disposable income), modified OECD-Scale, until 1990 only West Germany, incomes in prices of 2000 .

The values of various indices for both poverty and richness have overall been increasing in the 23 years of our analysis. Therefore, one could make the case of increasing poverty and affluence in Germany.

When taking a closer look at the development of the indices over time, one has to divide the data into the periods of 1983-1990 (only West Germany) and 1991-2006 (East and West Germany). Between 1990 and 1991, there was an increase in the number of rich people but a small decrease in richness measured by $R_{\beta=0.3}^{C h a}$ and $R_{\beta=3}^{C h a}$. Inequality increased according to the Gini index as well as poverty according to FGT, although the number of poor people decreased. 
How can this different behaviour of the headcount and the intensity measures be explained? The increasing number of people above the richness line is due to the overall decreased median income since East Germany has been covered by the data as of 1991. The non-standardized Medeiros measure $R^{M e d}$ indicates that richness decreased in absolute terms. Both effects, the absolute decline in richness and the higher number of rich people, contribute to the change in the intensity measures. The converging income differences between East and West Germany explain the overall increase in the measures of richness and poverty after reunification.

The new measures of richness can yield distinctively different results than the ordinary headcount index. As for the comparison of 1990 and 1991, from 1996 to 1997 the headcount index indicates an increase in richness whereas $R_{\beta}^{C h a}$ indicates a decrease. These effects can be explained by changes in the income structure. If $R_{H C}$ increases while $R_{\beta}^{C h a}$ decreases, the number of people above the richness line grows (headcount), whereas the intensity of richness and inequality is decreasing. This shows that a more sophisticated analysis of the development of richness yields different results than just counting the number of people above a certain affluence line. Therefore, we propose to use the new measures in addition to the headcount index for a more comprehensive analysis of richness.

\subsection{Poverty and affluence in Europe}

Our second application is the cross-country comparison of 26 European countries in 2005. These countries include the before 2007 EU-25 countries except Malta plus Iceland and Norway. ${ }^{19}$ Below, we use the term "Europe" for this group of 26 European countries. Table 2 presents the values of the various indices where the poverty (60\%) and richness (200\%) lines are computed for each country respectively. ${ }^{20}$

\footnotetext{
${ }^{19}$ The EU-SILC countries include: Austria (AT), Belgium (BE), Cyprus (CY), Czech Republic (CZ), Denmark (DK), Estonia (EE), Finland (FI), France (FR), Germany (DE), Greece (GR), Hungary (HU), Iceland (IS), Ireland (IE), Italy (IT), Latvia(LV), Lithuania (LT), Luxembourg (LU), Netherlands (NL), Norway (NO), Poland (PL), Portugal (PT) Slovak Republic (SK), Slovenia (SI), Spain (ES), Sweden (SE), United Kingdom (UK).

${ }^{20}$ One should note that due to these variable poverty and richness lines, the values of the European poverty and richness indices cannot be decomposed into the population weighted sum of individual country contributions. For this exercise, fixed European poverty and richness lines are necessary. However, this analysis (which can be obtained from the authors upon request) does not lead to new insights besides the trivial fact that richer (poorer) countries contribute c.p. more (less) to European richness and below (above) average to European
} 


\begin{tabular}{l|rr|rrr|rrrrr} 
& $p 50$ & $I_{G}$ & $\varphi^{H C}$ & $\varphi_{\alpha=1}^{F G T}$ & $\varphi_{\alpha=2}^{F G T}$ & $R^{H C}$ & $R_{\beta=0.3}^{C h a}$ & $R_{\beta=3}^{C h a}$ & $R^{M e d}$ & $R_{\alpha=2}^{F G T, T 2}$ \\
\hline Europe & 13.2 & 0.339 & 23.1 & 8.4 & 4.5 & 9.6 & 0.76 & 4.4 & 1073 & 9.2 \\
AT & 17.3 & 0.242 & 11.1 & 2.5 & 1.1 & 4.8 & 0.36 & 2.2 & 605 & 1.5 \\
BE & 16.7 & 0.264 & 14.9 & 3.7 & 1.5 & 5.0 & 0.38 & 2.2 & 695 & 17.5 \\
CY & 9.9 & 0.270 & 12.6 & 2.5 & 0.8 & 7.0 & 0.54 & 3.1 & 593 & 6.8 \\
CZ & 8.6 & 0.249 & 11.1 & 2.3 & 0.8 & 4.9 & 0.42 & 2.4 & 402 & 4.6 \\
DE & 14.8 & 0.255 & 11.3 & 3.2 & 1.6 & 5.3 & 0.43 & 2.4 & 749 & 5.9 \\
DK & 17.3 & 0.222 & 10.5 & 2.8 & 1.5 & 2.7 & 0.26 & 1.3 & 529 & 2.8 \\
EE & 6.4 & 0.321 & 18.2 & 5.7 & 2.9 & 10.5 & 0.88 & 5.2 & 549 & 4.3 \\
ES & 12.2 & 0.323 & 20.8 & 7.6 & 4.4 & 9.5 & 0.68 & 4.2 & 797 & 3.6 \\
FI & 16.0 & 0.251 & 10.4 & 1.8 & 0.6 & 4.6 & 0.42 & 2.2 & 893 & 10.9 \\
FR & 14.9 & 0.267 & 12.9 & 3.0 & 1.2 & 6.6 & 0.51 & 3.0 & 788 & 3.7 \\
GR & 11.9 & 0.343 & 21.5 & 6.6 & 3.3 & 11.0 & 1.01 & 5.5 & 1267 & 6.8 \\
HU & 6.3 & 0.330 & 17.4 & 5.0 & 2.4 & 8.4 & 0.90 & 4.3 & 758 & 16.2 \\
IE & 16.3 & 0.311 & 17.4 & 3.5 & 1.1 & 8.8 & 0.77 & 4.1 & 1595 & 16.7 \\
IS & 19.2 & 0.249 & 9.2 & 2.5 & 1.3 & 5.2 & 0.50 & 2.6 & 1099 & 5.4 \\
IT & 14.1 & 0.318 & 19.7 & 6.3 & 3.3 & 9.0 & 0.72 & 4.2 & 1033 & 5.4 \\
LT & 5.2 & 0.341 & 20.6 & 7.0 & 3.6 & 11.3 & 1.05 & 6.0 & 532 & 4.7 \\
LU & 27.2 & 0.275 & 13.7 & 3.1 & 1.1 & 7.9 & 0.60 & 3.7 & 1525 & 2.3 \\
LV & 5.0 & 0.380 & 22.3 & 7.9 & 4.2 & 13.7 & 1.38 & 7.1 & 809 & 16.7 \\
NL & 16.1 & 0.257 & 9.7 & 3.0 & 1.8 & 5.7 & 0.47 & 2.7 & 827 & 4.6 \\
NO & 21.7 & 0.268 & 9.6 & 2.5 & 1.2 & 4.0 & 0.49 & 2.2 & 2087 & 75.1 \\
PL & 5.3 & 0.332 & 19.3 & 5.7 & 2.7 & 11.4 & 1.00 & 5.8 & 530 & 5.2 \\
PT & 8.9 & 0.368 & 18.2 & 5.3 & 2.5 & 14.1 & 1.62 & 8.3 & 1641 & 16.4 \\
SE & 15.2 & 0.227 & 11.5 & 3.9 & 2.6 & 2.6 & 0.17 & 1.0 & 271 & 1.4 \\
SI & 13.1 & 0.227 & 10.0 & 2.2 & 0.8 & 4.4 & 0.26 & 1.7 & 291 & 0.6 \\
SK & 6.3 & 0.282 & 13.2 & 3.6 & 1.5 & 5.3 & 0.52 & 2.6 & 516 & 35.9 \\
UK & 17.2 & 0.318 & 19.3 & 5.8 & 2.9 & 9.3 & 0.72 & 4.2 & 1347 & 7.3
\end{tabular}

Table 2: Values (in \% except $p 50$ (in 1000 PPP-adjusted Euro), $I_{G}, R^{M e d}$ ) of the poverty and richness indices using EU-SILC data (Household equivalent disposable income), modified OECD-Scale, 2005, variable poverty and richness lines

The values of these indices vary significantly across countries. In general, poverty and richness are correlated with the level of inequality. The highest (lowest) values of richness in terms of the headcount measure can be found in Portugal (Sweden), whereas poverty is the highest (lowest) in Latvia (Iceland). When looking at more sophisticated measures of richness, these extremes remain. There are, however, differences, when comparing particular countries. We see, for instance, that there is a higher percentage of rich people in Luxembourg than in Norway (see $R_{H C}$ ). We also find higher values for $R_{\beta}^{C h a}$ in Luxembourg than in Norway. But it is the poverty. 
other way round for $R_{\alpha=2}^{F G T, T 2}$. One reason for this finding is the higher portion of people with income above $400 \%$ of the median income in Norway than in Luxembourg (see figure 3).

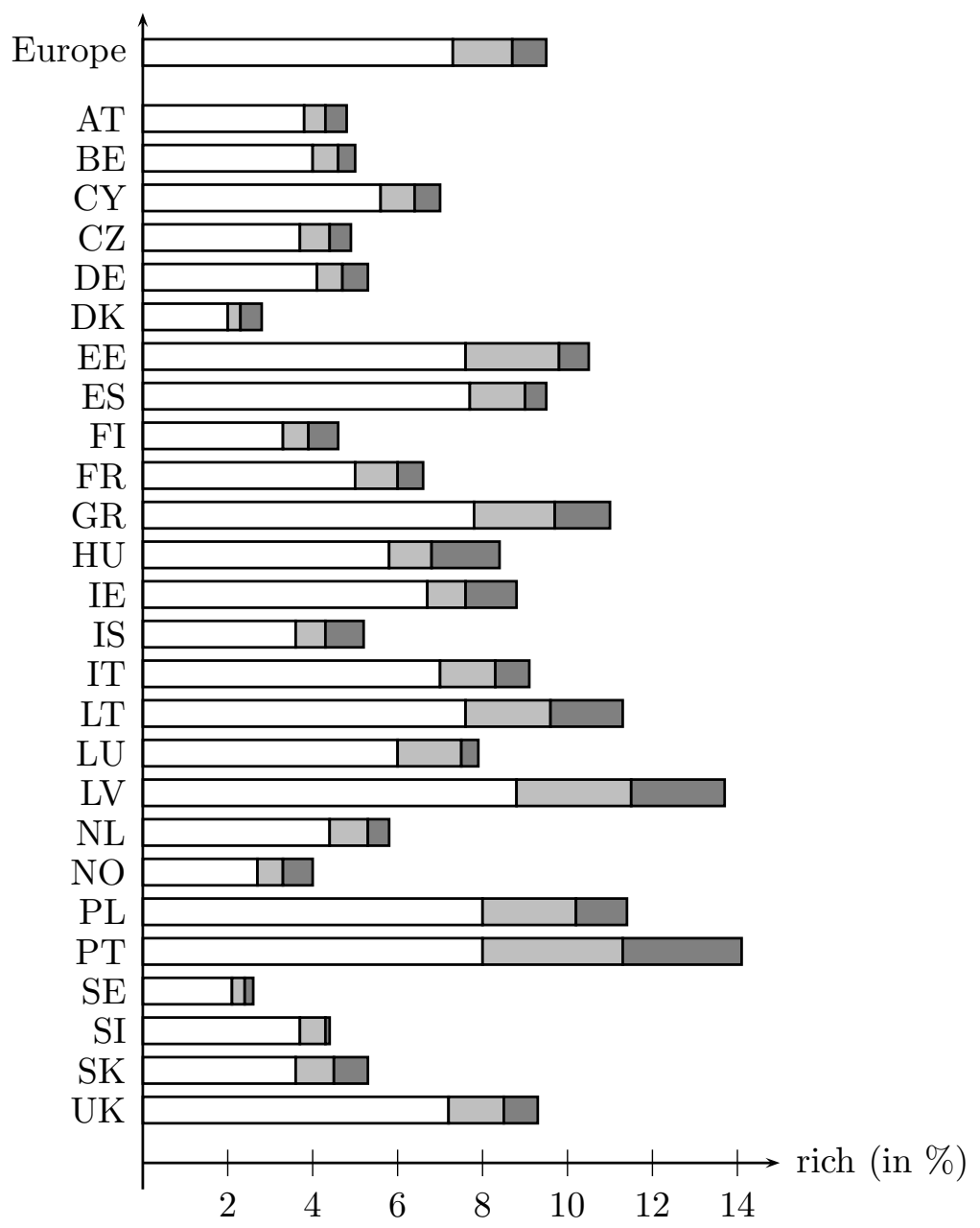

Figure 3: Percent of population with income between $200 \%$ and $300 \%$ (white), between $300 \%$ and $400 \%$ (light grey) and above $400 \%$ (dark grey).

When comparing Germany to Slovakia we find equal shares of rich persons $\left(R^{H C}\right)$ in the respective countries whereas the intensity of richness $\left(R_{\beta}^{C h a}\right)$ appears to be higher in Slovakia. Figure 3 shows that this can be explained by a bigger number of "less rich" people with income between $200 \%$ and $300 \%$ of the median in Germany. Further on, because of some people with extremely high incomes in Slovakia (the income share of the top $1 \%$ is $7.1 \%$ in Slovakia compared to $5 \%$ in Germany), the $R_{\alpha=2}^{F G T, T 2}$ index is also higher than in Germany.

The cross-country analysis yields 5 groups of countries in comparison to the EU average. In most cases we find neighboring countries in the same group. This classification is in line with the literature on welfare state typologies (see Arts and Gelissen (2002) for an overview). In general, 
Continental and Nordic welfare states are among the countries with low poverty and richness, whereas Eastern and Southern European countries as well as the Anglo-Saxon countries have high poverty and richness, indicating less redistribution in these welfare state regimes:

A) High poverty and high richness: Estonia, Greece, Lithuania, Latvia, Hungary, Ireland, Italy, Poland, Portugal, Spain, United Kingdom

B) Low poverty and low richness: Austria, Belgium, Cyprus, Czech Republic, Denmark, Finland, France, Germany, Iceland, Luxembourg, Netherlands, Norway, Slovak Republic, Slovenia, Sweden,

This classification of countries and their ranking, in general, remains robust when looking a different measures. However, there are some distinct differences across indices. For instance, Norway, Slovakia and Belgium are among the countries with relative low richness according to

all measures but $R_{\alpha}^{F G T, T 2}$ which ranks them first to third. On the other hand, Estonia, Spain, Lithuania and Poland are ranked much lower according to this convex measure.

In comparison to the other countries, the $R_{\alpha=2}^{F G T, T 2}$ index for Norway is extremely high. This high value is due to a few very, very rich persons in the Norwegian dataset. This is another argument for using a concave measure, since it depends on the characteristics of the datasets whether very high incomes are included or not.

\subsection{Poverty and richness effects of flat tax reform proposals in Ger- many}

The introduction of flat rate tax systems is widely seen as a reform which may boost efficiency, employment and growth through simplification and higher incentives, see Keen et al. (2007). However, these efficiency effects do not come for free. Inequality is likely to increase as a consequence of a flat tax reform implying redistribution from the poor to the rich. We try to shed some light on the question whether the gap between rich and poor is widening as a 
consequence of a flat tax reform by analyzing the effects of two flat tax reform proposals on poverty and richness in Germany as a third application of our measures of richness. ${ }^{21}$

\subsubsection{Current system and scenarios}

The basic steps for the calculation of the personal income tax under German tax law are as follows. ${ }^{22}$ The first step is to determine a taxpayer's income from different sources and to allocate it to the seven forms of income. For each type of income, the tax law allows for certain income related deductions. The second step is to sum up these incomes and to take losses carried forward into account to obtain the adjusted gross income. Third, deductions like contributions to pension plans or charitable donations are taken into account, which give taxable income as a result. Finally, the income tax is calculated by applying the tax rate schedule to taxable income. The tax liability $T$ is calculated on the basis of a mathematical formula which, as of the year 2006, is structured as follows:

$$
T(x)= \begin{cases}0, & \text { if } x \leq 7,664, \\ \left(883.74 \cdot \frac{x-7664}{10000}+1500\right) \cdot \frac{x-7664}{10000}, & \text { if } 7,664<x \leq 12,739, \\ \left(228.74 \cdot \frac{x-12739}{10000}+2397\right) \cdot \frac{x-12739}{10000}+989, & \text { if } 12,739<x \leq 52,151, \\ 0.42 \cdot x-7914, & \text { if } 52,151<x,\end{cases}
$$

where $x$ is the taxable income. For married taxpayers filing jointly, the tax is twice the amount of applying the formula to half of the married couple's joint taxable income.

The modeled flat tax reform scenarios are revenue-neutral combinations of tax base simplification with single tax rates as described in Fuest et al. (2008). Tax base simplification is modeled as the abolition of a set of specific deductions from the tax base included in the German income tax system. ${ }^{23}$ The first one has a low marginal tax rate of $25.1 \%$ and a basic tax allowance of

\footnotetext{
${ }^{21}$ In this paper we focus on questions of poverty and richness. We have analyzed the effects of these tax reforms on equity and efficiency elsewhere (see Fuest et al. (2008)).

${ }^{22} \mathrm{~A}$ more detailed description of the (modeling of) German tax rules can be found in Peichl and Schaefer (2006).

${ }^{23}$ Our choice of simplification measures is influenced by the German policy debate about existing tax breaks and deductions. Naturally, this analysis is restricted by the availability of data. The complete tax base adjustment bundle consists of the abolition of deductibility of commuting costs, the abolition of the saver's
} 
7664 euros (which corresponds to the current tax system). The second flat tax scenario has a higher marginal tax rate of $32 \%$ and a higher allowance of 12100 euros.

\subsubsection{Results}

The effects of the flat tax reform scenarios are calculated in the microsimulation model FiFoSiM. In this paper, we abstract from behavioral adjustments, i.e. we assume that the economic agents do not change their labor supply or savings in response to these tax reform scenarios. Table 3 presents the values of the measures for the different tax reform scenarios in the manner of the governmental reports on poverty and richness. In this methodology, the median and therefore the poverty and the richness line vary in each case. ${ }^{24}$

\begin{tabular}{l|ll|rrr|rrrrr} 
& $p 50$ & $I_{G}$ & $\varphi^{H C}$ & $\varphi_{\alpha=1}^{F G T}$ & $\varphi_{\alpha=2}^{F G T}$ & $R^{H C}$ & $R_{\beta=0.3}^{C h a}$ & $R_{\beta=3}^{C h a}$ & $R^{M e d}$ & $R_{\alpha=2}^{F G, T 2}$ \\
\hline status quo & 17945 & 0.289 & 18.1 & 4.1 & 1.4 & 8.0 & 0.55 & 3.4 & 917 & 2.0 \\
flat tax 1 & 17657 & 0.298 & 17.8 & 4.0 & 1.4 & 8.7 & 0.66 & 4.0 & 1136 & 3.2 \\
flat tax 2 & 17968 & 0.287 & 17.9 & 4.1 & 1.4 & 7.6 & 0.54 & 3.3 & 920 & 2.3
\end{tabular}

Table 3: Values (in $\%$ except $p 50, I_{G}, R^{M e d}$ ) of the poverty and richness indices using FiFoSiM (variable poverty and richness lines).

The values for the poverty indices do not change significantly for the revenue-neutral reform scenarios in comparison to the status quo, although the median income and thus the poverty line vary. ${ }^{25}$ The richness indices, however, change due to the fact that the tax base simplification measures affect higher income groups the most. For instance, the effective marginal tax rates are reduced for the highest income decile in scenario 2, whereas in the first scenario they are reduced in the three highest income deciles. The two reform scenarios change the $R_{\beta}^{C h a}$ indices into different directions. The flat tax with a high marginal rate and basic allowance (flat tax 2) very slightly decreases these indices, whereas the flat tax with a low marginal rate and basic

allowance, the restriction of labor income related expenses to $1000 €$ as well as the abolition of several tax allowances for age, single parents, children and deductions for tax accountancy costs, church tax and donations (charitable and for political parties).

${ }^{24}$ Our results, when using the same methodology, are in line with these reports (see Bundesregierung (2001) and Bundesregierung (2005)).

${ }^{25}$ When analyzing poverty, one has to take into account that the lowest deciles of the income distribution seldom pay income taxes, since there are always high basic tax allowances. Therefore, a reduction of income poverty through tax reforms is naturally restricted. A reform of the benefit system, like an increase in the social assistance for instance, would be a more effective measure. Further on, the minor distributional effects can be explained to some extent by the revenue neutrality of the flat tax reforms. 
allowance (flat tax 1) increases the $R_{\beta}^{C h a}$ measures. The increase in richness is unanimously confirmed by $R^{H C}, R^{M e d}$ and $R_{\alpha}^{F G T, T 2}$, but only for flat tax 1 . For flat tax $2, R^{H C}$ decreases, $R^{M e d}$ remains almost unchanged, whereas $R_{\alpha}^{F G T, T 2}$ increases. The latter effect for flat tax 2 can be explained by its design. The rather high marginal rate of $32 \%$ implies that only the "super rich" are getting richer than in the status quo, whereas some people who have been rich before change their status to non-rich. As $R_{\alpha}^{F G T, T 2}$ puts greater emphasis on the very top of the distribution, its value is increasing whereas $R_{\beta}^{C h a}$, which gives more importance to people just above the richness line, decreases.

A drawback of the approach of recomputing the (variable) poverty and richness lines is that an increasing measure of poverty (or a decreasing index of richness) does not necessarily indicate a worse situation for people with low (high) incomes as a result of the changing poverty (richness) line. To account for this weakness of relative measurement, we fix the poverty and richness lines at the value of the status quo taxation and recalculate the measures (see Table 4). ${ }^{26}$

\begin{tabular}{l|rrr|rrrrr} 
& $\varphi^{H C}$ & $\varphi_{\alpha=1}^{F G T}$ & $\varphi_{\alpha=2}^{F G T}$ & $R^{H C}$ & $R_{\beta=0.3}^{C h a}$ & $R_{\beta=3}^{C h a}$ & $R^{\text {Med }}$ & $R_{\alpha=2}^{F G T, T 2}$ \\
\hline status quo & 18.1 & 4.1 & 1.4 & 8.0 & 0.55 & 3.4 & 917 & 2.0 \\
flat tax 1 & 19.5 & 4.3 & 1.5 & 8.4 & 0.63 & 3.7 & 1086 & 3.0 \\
flat tax 2 & 17.9 & 4.1 & 1.4 & 7.6 & 0.55 & 3.3 & 924 & 2.3
\end{tabular}

Table 4: Values (in $\%$ except $R^{M e d}$ ) of the poverty and richness indices using FiFoSiM (fixed poverty and richness lines)

Not surprisingly, there is again no large variation in the values of the poverty measures for the flat tax with a high basic allowance (flat tax 2). However, the flat tax with the smaller existing basic allowance increases the poverty indices due to the abolishment of certain deductions like commuting costs and tax free bonuses for irregular working hours.

The flat tax alternative with low marginal rate and basic allowance (flat tax 1) increases the richness indices. The scenario with high marginal rate and basic allowance (flat tax 2) decreases the headcount measure as well as $R_{\beta}^{C h a}$, whereas $R_{\alpha}^{F G T, T 2}$ increases, i.e. the difference between the concave and the convex measure persists when comparing flat tax 2 to the status quo.

This latter example shows clearly that it depends on normative judgments whether flat tax scenario 2 increases or decreases richness. Therefore, if one has to judge which tax scenario is

\footnotetext{
${ }^{26}$ Median income and Gini coefficient remain unchanged compared to Table 3.
} 
preferable, e.g. in a sense that affluence should be limited, the decision depends on the chosen measure and its underlying assumptions.

To further analyze the effects of the flat tax reforms on population subgroups, we decompose the measures according to the family status of the household into four groups: single, single parents, and couples with and without children. The results are presented in Table 5. The population shares are given in brackets.

\begin{tabular}{l|ccr|rrrrr} 
& $\varphi^{H C}$ & $\varphi_{\alpha=1}^{F G T}$ & $\varphi_{\alpha=2}^{F G T}$ & $R^{H C}$ & $R_{\beta=0.3}^{C h a}$ & $R_{\beta=3}^{C h a}$ & $R^{\text {Med }}$ & $R_{\alpha=2}^{F G T, T 2}$ \\
\hline \multicolumn{8}{c}{ single, no children $(9 \%)$} \\
\hline status quo & 26.3 & 7.0 & 3.1 & 6.2 & 0.49 & 3.0 & 836 & 2.2 \\
flat tax 1 & 26.6 & 7.1 & 3.1 & 6.9 & 0.59 & 3.4 & 1073 & 3.5 \\
flat tax 2 & 26.1 & 7.1 & 3.1 & 6.2 & 0.51 & 3.0 & 894 & 2.7 \\
\hline \multicolumn{8}{c}{ single parents $(2 \%)$} \\
\hline status quo & 51.8 & 8.8 & 2.3 & 0.0 & 0.0 & 0.0 & 0 & 0.0 \\
flat tax 1 & 53.1 & 8.9 & 2.3 & 0.2 & 0.0 & 0.0 & 2 & 0.0 \\
flat tax 2 & 51.2 & 8.8 & 2.3 & 0.0 & 0.0 & 0.0 & 0 & 0.0 \\
\hline \multicolumn{8}{c}{ couple, no children $(52 \%)$} \\
\hline status quo & 14.4 & 3.7 & 1.3 & 11.4 & 0.82 & 5.1 & 1354 & 3.1 \\
flat tax 1 & 14.8 & 3.7 & 1.4 & 11.8 & 0.89 & 5.3 & 1546 & 4.3 \\
flat tax 2 & 14.3 & 3.6 & 1.3 & 11.1 & 0.79 & 4.9 & 1343 & 3.3 \\
\hline \multicolumn{8}{c}{ couple with children $(37 \%)$} \\
\hline status quo & 19.5 & 3.9 & 1.1 & 4.0 & 0.23 & 1.5 & 371 & 0.7 \\
flat tax 1 & 22.7 & 4.1 & 1.2 & 4.3 & 0.29 & 1.8 & 502 & 1.2 \\
flat tax 2 & 19.1 & 3.8 & 1.1 & 3.3 & 0.23 & 1.4 & 391 & 0.8
\end{tabular}

Table 5: Values (in $\%$ except $R^{M e d}$ ) of the poverty and richness indices using FiFoSiM (fixed poverty line) for subgroups

Expectedly, poverty is highest among single parents, more than half of whom are considered poor. Among couples without children, poverty is lowest. Except for couples with children, the indices do not change much when introducing a flat tax and the changes are in line with the results for the overall population.

Richness is highest among couples without children, whereas single parents are never among the rich. Again, we see that $R_{\beta}^{C h a}$ is in line with the headcount variation. As before, the convex index $R_{\alpha=2}^{F G T, T 2}$ moves in the opposite direction when flat tax 2 is compared to the status quo, as it puts more emphasis on the "super rich". 


\section{Conclusions}

In this paper we propose a new general class of affluence measures. In contrast to the headcount, the values of these new indices will increase with a rich person's income. We apply several indices to longitudinal data of Germany, cross-country data of Europe and we simulate different flat tax reform scenarios for Germany. We find that our measures of richness are a useful addition to pure headcount calculations.

We discover distinctive differences between headcount ratios and the new affluence indices in our longitudinal analysis of the development of richness in Germany. The new measures also clarify differing effects of the German reunification. While the number of rich people increased as a result of the decreasing median due to the inclusion of the East German population, richness in absolute terms decreased.

Our new measures reveal additional information beyond the proportion of rich people as the composition of "the rich" is also accounted for. This becomes evident when comparing affluence in countries across Europe. We show, for instance, structural differences between the rich population of Germany and of Slovakia, although the headcount index shows equal values in both countries. We also find that poverty and richness (compared to the local median) are rather high in Eastern and Southern European as well as Anglo-Saxon countries, but low in Continental and Nordic countries.

Not surprisingly, we find that the (revenue-neutral) flat tax reform scenarios have only small effects on poverty but some influence on richness. The results show the difference between concave and convex measurement. A flat tax with a low marginal tax rate and basic allowance decreases, whereas a flat tax with higher tax parameters increases our concave measure. The convex measure increases in both scenarios. This shows clearly the normative implication of the question whether a progressive transfer between rich persons should increase or decrease an affluence index.

From a theoretical point of view, we argue to use a concave weighting function to measure affluence. However, our general class is not limited to concave functions and we also define a convex measure to compare it with the concave index. The empirical applications, though, 
show that the different conclusions drawn from concave and convex measures are, in general, not that big. Nonetheless, in particular cases striking differences became evident. However, a qualification has to be made. When comparing concave and convex indices, one has to take into account that we based our analysis on survey data. If we use a convex function instead of a concave one, the estimates of the affluence indices depend extremely on the very high incomes. However, in many data sets, high incomes can be excluded (due to non-response), top-coded or anonymised, or less representative than other income ranges. One solution could be to construct series of top income data based on tax return data. However, it is generally not advisable to compare tax return data across countries as income tax systems differ considerably (see e.g. Atkinson and Piketty (2007)). Constructing a homogeneous cross-country top income dataset is subject to further research and could lead to important insights for future crosscountry comparisons. Still, to be able to apply the $R(\mathbf{x}, \rho)$ measures, information about the whole income distribution or at least the median income (for the richness line) is indispensable. Therefore, it would be useful to merge such a top income dataset with information of the bottom of the income distribution. Due to these restrictions we leave the choice of the weighting function up to the researcher, depending on the research question and the available data. In the end, this is a normative decision.

To sum up, our analysis showed that the measurement of richness is a complex field. The empirical applications revealed that the presented new richness measures lead to different results in comparison to the headcount index for some of the time periods, countries and reform scenarios. Our approach accounts for changes in the intensity of high incomes and, therefore, allows for a distinct analysis of structural changes at the top of the income distribution. We propose to use the new measures in addition to the headcount index for a more sophisticated analysis of richness.

\section{References}

Aaberge, R. and Atkinson, A. (2008). Top Incomes in Norway, Statistics Norway Discussion Paper No. 552. 
Arts, W. A. and Gelissen, J. (2002). Three worlds of welfare capitalism or more? A state-ofthe-art report, Journal of European Social Policy 12(2): 137-158.

Atkinson, A. B. (1997). Measurement of Trends in Poverty and the Income Distribution, Cambridge Working Papers in Economics, number 9712.

Atkinson, A. B. (2005). Comparing the distribution of top incomes across countries, Journal of the European Economic Association 3(2-3): 393-401.

Atkinson, A. and Piketty, T. (2007). Top Incomes over the Twentieth Century, Oxford University Press, Oxford.

Atkinson, T., Bourguignon, F., O'Donoghue, C., Sutherland, H. and Utili, F. (2002). Microsimulation of Social Policy in the European Union: Case Study of a European Minimum Pension, Economica 69: 229-243.

Bundesregierung (2001). Lebenslagen in Deutschland - Der erste Armuts- und Reichtumsbericht der Bundesregierung, http://www.bmas.bund.de/.

Bundesregierung (2005). Lebenslagen in Deutschland - Der zweite Armuts- und Reichtumsbericht der Bundesregierung, http://www.bmas.bund.de/.

Bundesregierung (2008). Lebenslagen in Deutschland - Der dritte Armuts- und Reichtumsbericht der Bundesregierung, http://www.bmas.bund.de/.

Chakravarty, S. and Muliere, P. (2004). Welfare Indicators: A Review and New Perspectives 2. Measurement of Poverty, Metron-International Journal of Statistics LXII (2): 247-281.

Chakravarty, S. R. (1983). A new index of poverty, Mathematical Social Sciences 6: 307-313.

de Vos, K. and Zaidi, A. (1997). Equivalence Scale Sensitivity of Poverty Statistics for the Member States of the European Community, Review of Income and Wealth 3: 319-333.

Dell, F. (2005). Top incomes in Germany and Switzerland over the twentieth century, Journal of the European Economic Association 3(2-3): 412-421. 
Foster, J., Greer, J. and Thorbecke, E. (1984). A class of decomposable poverty measures, Econometrica 52: 761-766.

Fuest, C., Peichl, A. and Schaefer, T. (2008). Is a flat tax reform feasible in a grown-up democracy of Western Europe? A simulation study for Germany, International Tax and Public Finance 15: 620-636.

Gupta, A. and Kapur, V. (2000). Microsimulation in Government Policy and Forecasting, North-Holland, Amsterdam.

Haisken De-New, J. and Frick, J. (2003). DTC - Desktop Compendium to The German SocioEconomic Panel Study (GSOEP).

Hanesch, W., Krause, P. and Bäcker, G. (2000). Armut und Ungleichheit in Deutschland, Rowohlt, Reinbek.

Harding, A. (1996). Microsimulation and public policy, North-Holland, Elsevier, Amsterdam.

Harsanyi, J. C. (1977). Morality and the theory of rational behavior, Social Research 44: 623656.

Keen, M., Kim, Y. and Varsano, R. (2007). The 'flat tax(es)': Principles and experience, International Tax and Public Finance forthcoming.

Krause, P. and Wagner, G. (1997). Reichtum in Deutschland - Die Gewinner in der sozialen Polarisierung, in E.-U. Huster (ed.), Einkommens-Reichtum und Einkommens-Armut in Deutschland, 2. edn, Campus Verlag, Frankfurt, pp. 65-88.

Lockwood, P. and Kunda, Z. (1997). Superstars and Me: Predicting the Impact of Role Models on the Self, Journal of Personality and Social Psychology 73 (1): 91-103.

Medeiros, M. (2006). The rich and the poor: the construction of an affluence line from the poverty line, Social Indicators Research 78: 1-18.

Merz, J. (2004). Einkommens-Reichtum in Deutschland - Mikroanalytische Ergebnisse der Einkommensteuerstatistik für Selbständige und abhängig Beschäftigte, Perspektiven der Wirtschaftspolitik 5(2): 105-126. 
OECD (2006). Fundamental reform of personal income tax, OECD Tax Policy Studies 13.

Peichl, A. and Schaefer, T. (2006). Documentation FiFoSiM: Integrated Tax Benefit Microsimulation and CGE Model, Finanzwissenschaftliche Diskussionsbeitrge Nr. 06 - 10, Universitt zu Kln.

Piketty, T. (2005). Top income shares in the long run: An overview, Journal of the European Economic Association 3(2-3): 382-392.

Piketty, T. and Saez, E. (2006). The evolution of top incomes: a historical and international perspective, American Economic Review, Papers and Proceedings 96 (2): 200-205.

Roine, J. and Waldenström, D. (2008). The evolution of top incomes on an egalitarian society: Sweden, 1903-2004, Journal of Public Economics 92: 366-387.

Saez, E. (2005). Top incomes in the United States and Canada over the twentieth century, Journal of the European Economic Association 3(2-3): 402-411.

Saez, E. and Veall, M. (2005). The Evolution of High Incomes in Northern America: Lessons from Canadian Evidence, America Economic Review 95: 831-849.

Sen, A. (1976). Poverty: An Ordinal Approach to Measurement, Econometrica 44: 219-231.

SOEP Group (2001). The German Socio-Economic Panel (GSOEP) after more than 15 years - Overview, Vierteljahrshefte zur Wirtschaftsforschung 70: 7-14.

Wagenhals, G. (2004). Tax-benefit microsimulation models for Germany: A Survey, $I A W$ Report / Institut fuer Angewandte Wirtschaftsforschung (Tübingen) 32(1): 55-74.

Watts, H. (1968). An Economic Definition of Poverty, in D. Moynihan (ed.), On Understanding Poverty: Perspectives from the Social Sciences, Basic Books, New York.

Zheng, B. (1997). Aggregate poverty measurement, Journal of Economic Surveys 11(2): 123162. 